\title{
The Effects of Different HIV Type 1 Strains on Human Thymic Function
}

\author{
PING YE, ${ }^{1}$ ATHENA P. KOURTIS, ${ }^{2}$ and DENISE E. KIRSCHNER ${ }^{1}$
}

\begin{abstract}
Studies of HIV-1-infected humans indicate that the thymus can be infected by HIV-1. In some of these patients, there is a significant $\mathrm{CD4}^{+} \mathrm{T}$ cell decline and a faster disease progression. This phenomenon is more evident in pediatric patients who depend heavily on their thymus for generation of new $\mathbf{T}$ cells. We hypothesize that HIV-1 causes $T$ cell regenerative failure within the thymus, which has a profound impact on disease progression. Building on our established human thymopoiesis model, we include dynamic interactions between different HIV-1 strains (R5 and X4) and thymocytes. Our results predict that thymic infection with different HIV-1 strains induces thymic dysfunction to varying degrees, contributing to differences in disease progression as observed in both HIV-1-infected children and adults. Thymic infection in children is more severe than in adults, particularly during X4 infection. This outcome is likely due to both a higher viral load and a more active thymus in pediatric patients. Our results also indicate that a viral strain switch from R5 to $\mathrm{X} 4$ induces further deterioration in thymopoiesis. We predict that both viral and host factors play key roles in controlling thymic infection, including strain virulence and health status of the thymus.
\end{abstract}

\section{INTRODUCTION}

$\mathbf{H}$ IV-1 DISEASE IS MARKED by progressive loss of $\mathrm{CD}^{+}{ }^{+} \mathrm{T}$ cells leading to immunodeficiency and death usually due to opportunistic infections. $\mathrm{CD}^{+}{ }^{+} \mathrm{T}$ cell decline in blood may result from either a reduction in $\mathrm{T}$ cell production in the thymus, altered $\mathrm{T}$ cell migration patterns, or a decrease in $\mathrm{T}$ cell lifespan. We have previously explored the second and third hypotheses showing that altered lymphocyte circulation patterns may contribute to the loss of $\mathrm{CD} 4^{+}$T cells, ${ }^{1,2}$ as enhanced apoptosis of bystander cells and immune activation lead to increased cell death. ${ }^{3-5}$ In this paper we focus on the first hypothesis, namely the role of the thymus during HIV-1 infection.

The thymus is the primary lymphoid organ generating recent thymic emigrants (RTE) to the periphery. T cell receptor excision circles (TREC) were recently developed as a marker for RTE in humans. ${ }^{6,7}$ Clinical studies of HIV-1-infected children and adults indicate that the thymus is affected by HIV-1-induced morphological changes, including decrease in total thymocyte numbers and enhanced involution. ${ }^{8-10}$ Decreases in naive $\mathrm{T}$ cells and TREC concentrations are documented in both
HIV-1-infected pediatric and adult patients., ${ }^{6,11,12}$ Thymic dysfunction and early thymic involution have been associated with rapid disease progression in a subset of infants infected perinatally with HIV-1. ${ }^{13-15}$

Mechanisms associated with thymic HIV-1 infection have been extensively studied in several in vivo and in vitro systems, including SCID-hu thy-liv mouse, human thymic organ culture, thymocyte-epithelial cell culture, SIV/SHIV infection of nonhuman primates, and FIV infection of felines. As background, we summarize the results of these studies as follows. The HIV1 receptor, CD4, is expressed on nearly all thymocytes. Thus, coreceptor expression becomes a determinant of HIV-1 entry. CCR5 is detected at low levels on mature thymocytes, while CXCR4 is detected at high levels on the surface of almost all thymocytes. ${ }^{16-19}$ Thus it is not surprising that $\mathrm{X} 4$ viral strains (that use the CXCR4 coreceptor) infect almost all thymocytes, whereas R5 strains (that use the CCR5 coreceptor) infect only mature thymocytes. ${ }^{16,20,21}$ The more cytopathic X4 strains replicate faster and to higher levels, and also aggressively destroy thymocytes, while the slowly replicating, noncytopathic R5 strains initially trigger destruction of stromal cells, and then

\footnotetext{
${ }^{1}$ Department of Microbiology and Immunology, The University of Michigan Medical School, Ann Arbor, Michigan 48109.

${ }^{2}$ Eastern Virginia Medical School, CONRAD/CDC, Atlanta, Georgia 30341.
} 
spread to thymocytes. ${ }^{20,22}$ These studies suggest that in vivo coreceptor specificity and entry efficiency are critical determinants of HIV-1 pathogenesis in the thymus.

We have previously published a mathematical model exploring the effect of thymic infection on the course of pediatric AIDS disease progression. ${ }^{23}$ Our results indicate that thymic infection can augment peripheral HIV-1 infection by acting as a source of both virus and infected $\mathrm{T}$ cells. Here, we construct a new mathematical model to illustrate the dynamic interactions between different HIV-1 strains and relevant subsets of thymocytes. We hypothesize that thymic infection with either R5 or X4 strains causes thymic dysfunction, contributing to differences in disease progression as seen in both HIV1 -infected children and adults. Underlying mechanisms include the pattern of coreceptor expression on thymocytes, the virulence of viral strains, and the ability of thymocytes to support viral replication. To capture the role of the thymus in children as well as thymus involution in adults, separate models have been generated to capture differences in pediatric and adult patients. These virtual human models of thymic infection with HIV-1 serve as both quantitative and qualitative tools to measure the contribution of the thymus to the peripheral $\mathrm{T}$ cell pool under different viral strain infection scenarios, as well as to explore the pathogenic dynamics of HIV-1 strains on thymocytes.We can further apply these models to predict how the thymus will contribute to T cell recovery during HIV1 treatment.

\section{MATERIALS AND METHODS}

\section{Model development}

The HIV-1 R5 strains use CCR5 as a coreceptor, and the X4 strains use CXCR4, while the R5X4 strains are able to use both coreceptors with comparable efficiency. ${ }^{24} \mathrm{R} 5$ is the most commonly transmitted strain, while X4 and (or) R5X4 strains evolve as the dominant species in about $50 \%$ of patients..$^{25,26} \mathrm{X} 4$ and R5X4 are generally more cytopathic and correlate with accelerated disease progression. ${ }^{27,28}$ Our goal is to explore whether thymic infection with HIV-1 R5 or X4 strains could explain varied disease progression patterns in pediatric and adult patients.

A diagram of our model illustrating host cell and viral dynamics in the thymus is shown in Figure 1. This model is constructed based on our previous human thymopoiesis model. ${ }^{7} \mathrm{We}$ consider both the normal thymopoiesis process and infection of thymocyte subsets by either R5 or X4 strains. Model equations, variables, and parameters are discussed in the Appendix.

\section{RESULTS}

\section{Virtual pediatric infection}

Pediatric infection with HIV-1 occurs chiefly through transmission from the mother during delivery or in late-stage pregnancy. ${ }^{29}$ Our model could account for prenatal infection, but

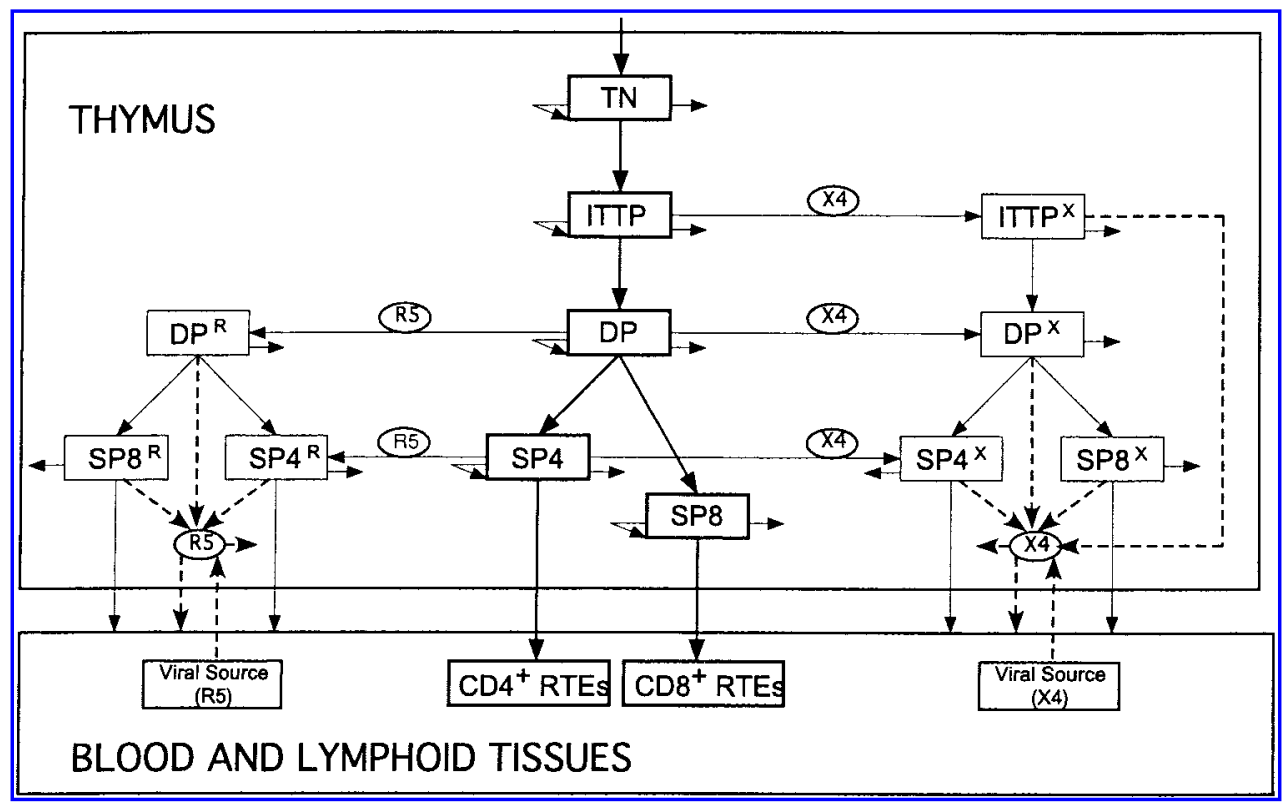

FIG. 1. The model of thymic HIV-1 infection with R5 or X4 strains. Rectangles represent cell populations and ellipses represent viral populations. Cell dynamics are illustrated using solid lines and viral dynamics are illustrated using dashed lines. Five uninfected thymocyte subsets are triple negative (TN), intrathymic T progenitor (ITTP), double positive (DP), CD4 single positive (SP4), and CD8 single positive (SP8) cells. SP4 and SP8 cells emigrate to the periphery as RTE. Added to normal healthy thymopoiesis dynamics ${ }^{7}$ are infection and enhanced death of uninfected thymocytes. Three R5-infected cell subsets and four X4infected cell subsets are tracked: $D P^{R}, S P 4^{R}, S P 8^{R}, I T T P^{X}, D P^{X}, S P 4^{X}$, and $S P 8^{X}$ cells, respectively. They are generated by infection and/or differentiation. Each of these infected cell populations differentiates, dies, and emigrates to the periphery. Two viral populations are tracked in the thymus: R5 and X4. Virus flows in from blood and is also produced by infected cells. Virus also emigrates to the periphery and is cleared within the thymus. 
we assume pediatric HIV-1 infection initiates at birth for simplicity. One study indicates that TREC concentrations decline fairly quickly after the onset of HIV-1 infection in infants. ${ }^{12}$ Thus we model HIV-1 infection occurring within the thymus initiating at birth (i.e., birth $=$ infection time 0 ), the same time as newborns are infected with HIV-1.

We simulate total thymocytes and SP4/SP8 ratio in healthy, uninfected individuals during the first 2 years of life as a control (solid lines, Fig. 2). Total thymocytes increase to their maximum at the age of one, then decline afterward (Fig. 2A). The ratio of SP4/SP8 remains constant (Fig. 2B). During infection with either R5 or X4 strains, total numbers of uninfected thymocytes initially drop sharply, and then rebound and level off. This is due to continual thymic growth in the first year of life. After the first year, total uninfected thymocytes decrease, consistent with thymic involution(Fig. 2A). HIV-1 infection within the thymus reduces the number of SP4 cells to a greater extent than SP8 cells, resulting in a decrease in the SP4/SP8 ratio (Fig. $2 \mathrm{~B})$. This is consistent with a remarkable depletion of SP4 cells and a relative increase in SP8 cells as seen in studies of both humans and SCID-hu mice. ${ }^{8,30,31}$ A decrease in the SP4/SP8 ratio likely contributes to the $\mathrm{CD} 4^{+} / \mathrm{CD}^{+}$ratio inversion occurring in the blood, a characteristic of HIV-1 infection. ${ }^{32}$ Thymic infection with X4 strains depletes total thymocytes and decreases the SP4/SP8 ratio to a greater level as compared with R5 infection.

Infection in the thymus establishes quickly and the number of infected cells correlates with viral load within the thymus. Infection with X4 occurs faster, and both viral load and the number of infected cells are greater than during infection with
R5 (Fig. 2C and D). These results are similar to different infection scenarios in the thymus of SCID-hu mice when inoculated with R5 or X4 strains. ${ }^{16,20,22}$ One important model prediction for children infected during the first year of life is that $\mathrm{X} 4$ strain replication is enhanced due to growth of the thymus. Thymic growth provides a greater number of $\mathrm{X} 4$ target cells generating more infected thymocytes and higher viral load in the thymus (Fig. 2C and D).

The rate of disease progression among HIV-1-infected children varies greatly and the underlying mechanisms that determine this are not fully understood. Most pediatric patients follow a disease progression pattern similar to that seen in adults, except for a higher viral load. ${ }^{33}$ However, some infants infected perinatally with HIV-1 develop AIDS very early in life and have lymphocyte depletion pattern similar to infants born with congenital absence or maldevelopment of the thymus known as DiGeorge syndrome (characterized by very low levels of $\mathrm{CD} 4^{+}$, $\mathrm{CD}^{+} \mathrm{T}$ cells, and $\mathrm{CD}^{+} \mathrm{B}$ cells).$^{13,34}$ This group of infants appears to have a peripheral blood immunophenotypic profile corresponding to thymic dysfunction, likely caused by HIV-1. Blood CD4 ${ }^{+} \mathrm{T}$ cell data from Kourtis et al. ${ }^{13}$ representing 227 infants exposed to HIV-1 are presented in three settings: those classified with a "thymic dysfunction profile" who have very low $\mathrm{CD}^{+}{ }^{+} \mathrm{T}$ cell counts and faster disease progression (Fig. $3 \mathrm{~A}$, squares), those without the "thymic dysfunction profile" who have low $\mathrm{CD}^{+}{ }^{+} \mathrm{T}$ cell counts and typical HIV-1 disease progression patterns (Fig. 3A, circles), and uninfected controls with normal $\mathrm{CD}^{+}{ }^{+} \mathrm{T}$ cell counts (Fig. 3A, triangles). Both viral and host factors have been implicated in those different patterns. $^{23}$

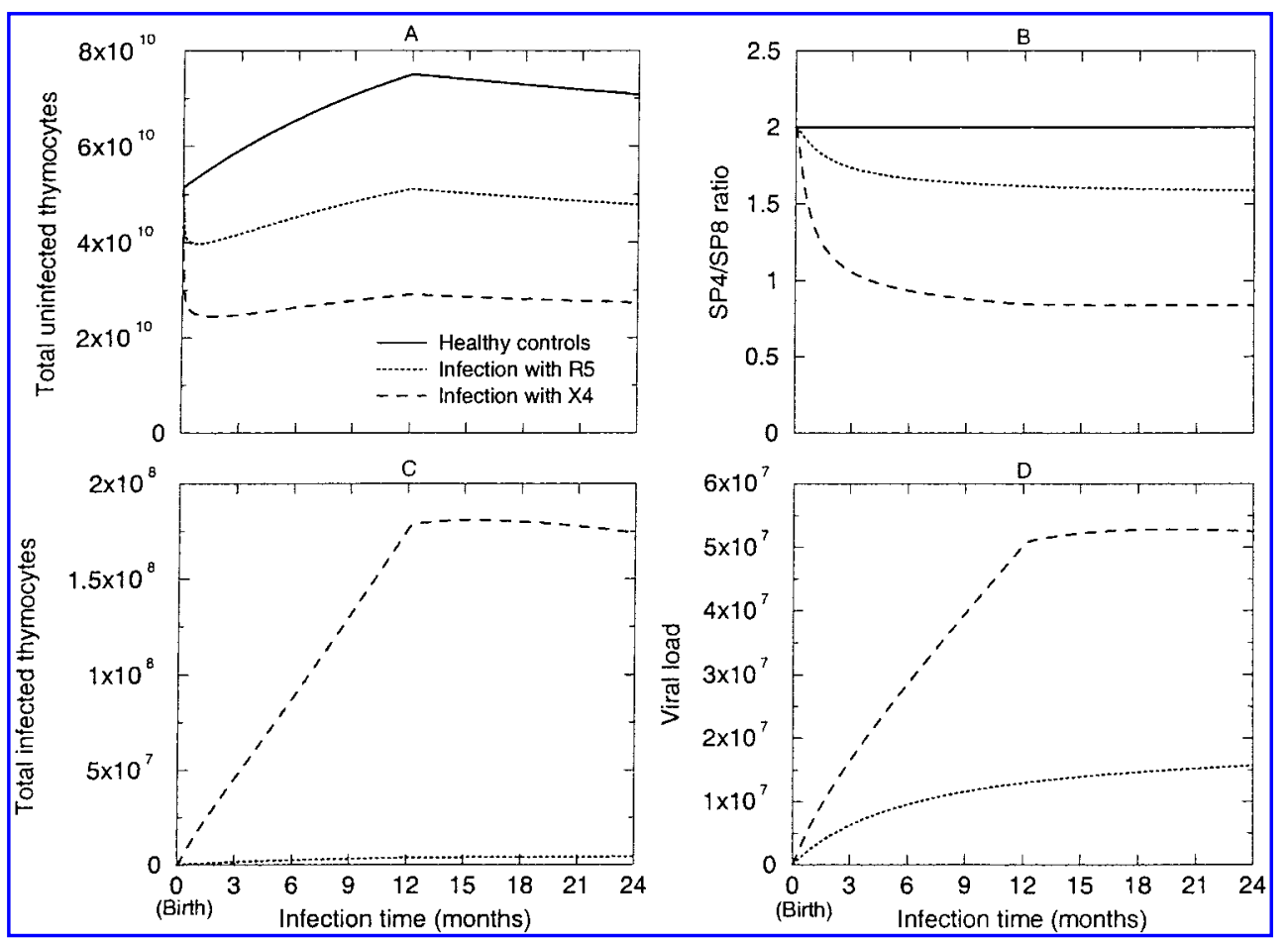

FIG. 2. Virtual pediatric thymic HIV-1 infection. Two infection scenarios are simulated: infection with either R5 (dotted lines) or X4 strains (dashed lines). A simulation of healthy, uninfected individuals serves as a control (solid lines). (A) The total uninfected thymocytes, (B) the SP4/SP8 ratio, (C) the total infected thymocytes by strain, and (D) the intrathymic viral load. 


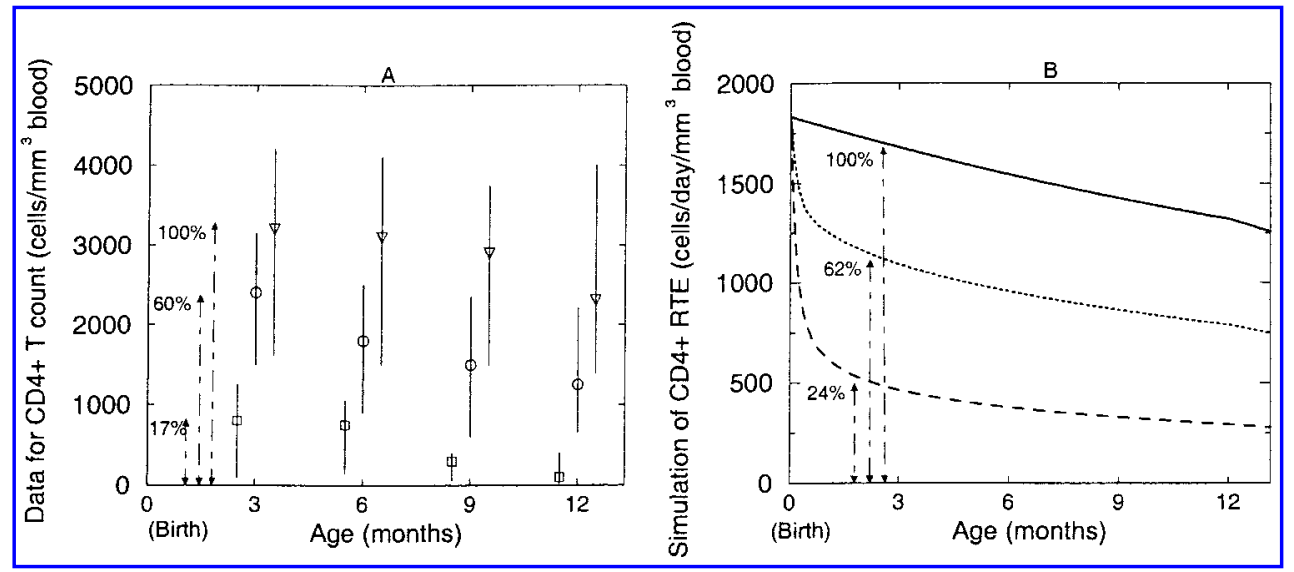

FIG. 3. Simulations of CD $4^{+}$RTE exported from the thymus predict CD4 ${ }^{+} \mathrm{T}$ cell counts in blood of pediatric patients. (A) Medians and ranges of $\mathrm{CD} 4^{+} \mathrm{T}$ cell counts in three groups of children: an HIV-1-exposed uninfected cohort (triangles), an HIV1 -infected cohort without thymic dysfunction (circles), and an HIV-1-infected cohort with a thymic dysfunction profile (squares). ${ }^{13}$ (B) Three model simulations of the number of $\mathrm{CD}^{+}{ }^{+}$RTE per day in healthy controls (solid lines) and during infection with either R5 (dotted lines) or X4 (dashed lines) strains. The dynamics of blood CD4 ${ }^{+}$T cells and simulations of CD4 ${ }^{+}$RTE are correlated as seen by similar percentage reductions over time by infection type.

Our virtual infection model suggests that the bimodal pattern of disease progression of pediatric patients may be explained by thymic infection with different viral strains. To test this, we simulate the number of $\mathrm{CD}^{+}{ }^{+} \mathrm{RTE}$ exported per day in three scenarios: healthy controls, patients infected with R5, and patients infected with $\mathrm{X} 4$. To capture changes in blood volume that occur over time in children, the rate of exported $\mathrm{CD}^{+}{ }^{+}$RTE is divided by blood volume, ${ }^{7}$ to convert units to cells/day $/ \mathrm{mm}^{3}$ blood (Fig. 3B). Each of the model simulations of $\mathrm{CD}^{+}{ }^{+} \mathrm{RTE}$ per day during health, R5 infection, and X4 infection has the same overall pattern change in peripheral $\mathrm{CD} 4^{+} \mathrm{T}$ cells as compared to the clinical study of uninfected children, HIV-1-infected children without thymic dysfunction, and HIV-1-infected children with a thymic dysfunction profile (Fig. 3). ${ }^{13}$ These graphic results cannot be superimposed directly as the peripheral $\mathrm{CD} 4^{+} \mathrm{T}$ cell count will be larger than the number of $\mathrm{CD}^{+}$RTE emigrating from the thymus per day; however, their trends are clearly comparable. For example, during $\mathrm{R} 5$ and $\mathrm{X} 4$ infection, the rates of production of $\mathrm{CD}^{+}{ }^{+} \mathrm{RTE}$ decrease to 62 and $24 \%$, respectively, of their normal values during the first year of life. These decreases are correlated with CD4 ${ }^{+} \mathrm{T}$ cells in the blood, which decrease to 60 and $17 \%$ of their normal values in children without thymic dysfunction and with thymic dysfunction, respectively (Fig. 3).

In newborns, the thymus serves to establish the peripheral $\mathrm{T}$ cell pool by contributing the majority of newly generated T cells to the blood-lymphoid system (represented by the number of RTE). ${ }^{35}$ Thus, we believe the immunophenotypes shown in the blood can reflect what occurs in the thymus in young children. Our results indicate that a decrease in thymic output due to HIV1 infection induces differing levels of $\mathrm{CD}^{+}{ }^{+} \mathrm{T}$ cell decline in the peripheral system. Therefore, the thymus plays a critical role in regulating $\mathrm{CD}_{4}{ }^{+} \mathrm{T}$ cell homeostasis in newborns during HIV-1 infection. This is likely a key mechanism contributing to different disease progression patterns observed in pediatric patients. X4 strains may be especially relevant in children, as their thymuses are active and CXCR4 is the predominant coreceptor expressed on thymocytes.

\section{Virtual adult infection}

To consider a virtual adult thymic infection experiment, we follow a procedure similar to that outlined for the pediatric model above. The thymus of a 30-year-old person is used to study virtual adult infection (i.e., age $30=$ infection time 0 ). The maximal number of thymocytes in thymic epithelial space (TES) and the cell source from the bone marrow are chosen to reflect an adult at that age. ${ }^{7}$ Our model predicts that in a 30 year-old person the number of total thymocytes is $18.5 \%$ of total thymocytes at age one (note that this calculation can be performed for a person of any age).

The virtual model of adult infection indicates that the number of total uninfected thymocytes drops quickly during infection with either R5 or X4 strains (Fig. 4A). This is a result of both infection and the normal thymic involution process. The SP4/SP8 ratio decreases more slowly and to a lesser extent as compared with pediatric infection (compare Fig. 2B with Fig. 4B). Total infected thymocytes correlate with intrathymic viral load (Fig. 4C and D). A bimodal pattern of R5 or X4 infection in adults is similar to pediatric infection. However, adult thymic infection with X4 strains causes less detrimental effects as compared with that of pediatric X4 infection (compare Figs. 2 and 4). Infection in adults with $\mathrm{X} 4$ after 1 year generates a 14.2fold greater number of infected thymocytes and 1.2-fold higher intrathymic viral load as compared with R5 infection (Fig. 4C and D). These ratios increase to 46.9-fold and 3.9-fold respectively during pediatric infection (Fig. $2 \mathrm{C}$ and $\mathrm{D}$ ). This suggests that X4 strains are more destructive in children, which may result from higher viral loads and active thymopoiesis with proportionately higher CXCR4 expression on thymocytes.

It has been shown that TREC concentrations are variable in adults after primary HIV-1 infection. ${ }^{11}$ Our model results (Fig. 4) suggest that adult thymic infection with different viral strains 


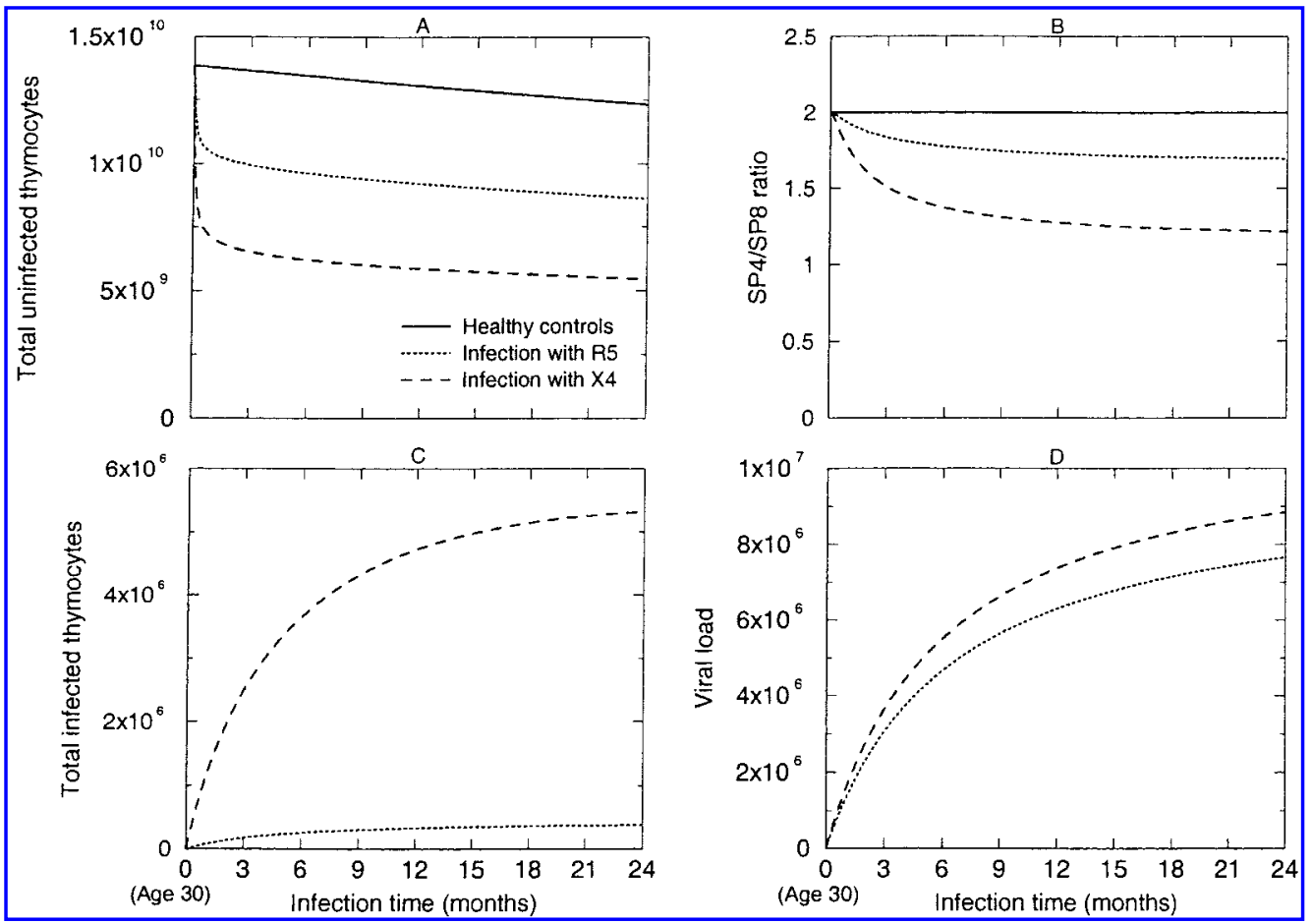

FIG. 4. Virtual adult thymic HIV-1 infection. Two infection scenarios are simulated: infection with either R5 (dotted lines) or X4 (dashed lines) strains. A simulation of healthy, uninfected individuals serves as a control (solid lines). (A) The total uninfected thymocytes, (B) the SP4/SP8 ratio, (C) the total infected thymocytes by strain, and (D) the intrathymic viral load.

could explain this variation. Although the X4 (R5X4) strains are rarely transmitted, primary infection with the X4 (R5X4) strains have been observed, for example, in individuals homozygous and heterozygous for CCR $5 \Delta 32 .^{36,37}$ Other factors, such as immune system activation in response to HIV-1 infection, may also be relevant for interpreting TREC level variations.

We summarize our infection model results in Table 1 and provide experimental data for comparison. ${ }^{38,39}$ In both pediatric and adult patients, our model indicates that infection with different viral strains can explain varying degrees of thymic dysfunction. X4 strains are significantly more destructive to the thymus as compared with R5. When comparing the same viral strain thymic infection scenarios in children and adults, pediatric infection is more severe than in adults, especially during $\mathrm{X} 4$ infection. This is likely due to higher viral load and con- tinual growth of the thymus providing more target cells in children.

Recently, two primary HIV-1 isolates have been characterized to infect cells only through cell surface CD8 molecules. ${ }^{40}$ We performed experiments of direct infection of SP8 cells by either R5 or X4 strains using our virtual pediatric and adult model, while fixing all other processes as before (data not shown). If SP8 cells can be infected by HIV-1, our simulations indicate that intrathymic viral load and total infected cells increase by approximately $50 \%$ during pediatric X4 infection. However, direct infection of SP8 cells does not change infection outcomes in pediatric or adult R5 infection (data not shown). This is explained by the lower virulence of R5 strains. Simulations of adult X4 infection show little change when SP8 cells are infected likely due to few target cells available in adults (data not shown). These results lend further support to

Table 1. Simulation Values at Year 2 of Virtual Infection Compared with Experimental Data

\begin{tabular}{|c|c|c|c|c|c|c|}
\hline \multirow[b]{2}{*}{ Ratio } & \multicolumn{2}{|c|}{ Pediatric model } & \multicolumn{2}{|c|}{ Adult model } & \multirow[b]{2}{*}{ Data } & \multirow[b]{2}{*}{ References } \\
\hline & $R 5$ & X4 & $R 5$ & X4 & & \\
\hline$\frac{\text { Exported cells in an infected individual }}{\text { Exported cells in a healthy individual }}(\%)$ & 63 & 32 & 63 & 36 & $10-60$ & 6,11 (human) \\
\hline$\frac{\text { Infected thymocytes in an infected individual }}{\text { Total thymocytes in an infected individual }}(\%)$ & 0.009 & 0.632 & 0.004 & 0.098 & $0.001-1$ & 38,39 (monkey) \\
\hline$\frac{\text { SP4 in an infected individual }}{\text { SP8 in an infected individual }}$ & 1.59 & 0.84 & 1.70 & 1.22 & 0.5 & 31 (SCID-hu mouse) \\
\hline
\end{tabular}


the hypothesis that $\mathrm{X} 4$ strains are highly pathogenic in children.

\section{Viral strain switch in adults}

Establishment of initial HIV-1 infection is believed to occur with R5 strains in the majority of individuals. ${ }^{26}$ However, due to viral mutation and evolution, the viral pool becomes more heterogeneous with progressive disease. X4 (R5X4) strains are dominant in about $50 \%$ of patients, and have been correlated with greater $\mathrm{CD} 4^{+}$T cell depletion. ${ }^{26-28}$ To explore the effects of a viral strain switch on thymic infection, we alter the influx of R5 and X4 viral strains from blood into the thymus to capture a viral strain switch occurring in the periphery. In this work, we do not make any assumptions as to what induces this switch, but only model the events after the switch occurs.

We simulate a viral strain switch from R5 to X4 occurring 6 months after infection in a 30-year-old person. We assume the viral strain switch from R5 to X4 occurs over a period of 6 months based on a study of HIV-1-infected patients undergoing highly active antiretroviral therapy (HAART) who experienced a viral strain switch back from X4 to R5 that occurred in 6 months on average. ${ }^{41}$ The strain switch invokes a quick drop in total uninfected thymocytes and the SP4/SP8 ratio (Fig. $5 \mathrm{~A}$ and $\mathrm{B}$ ), approaching the level seen in X4-only infection (Fig. $4 \mathrm{~A}$ and $\mathrm{B})$. Both viral strains and the corresponding infected cell populations are present after the switch. X4-infected thymocytes are more than 100-fold higher than when compared with R5-infected thymocytes, likely due to higher infection rates for X4 strains (Fig. 5C). X4 strains are dominant strains and their viral load is approximately 10-fold higher than R5 (Fig. 5D). Varying the start time of the switch results in similar outcomes (data not shown). Varying the duration that a switch occurs induces curve changes during the switch period, but the same end results are obtained (data not shown). A viral strain switch in children yields a pattern similar to that seen in adults (data not shown). These results indicate that a viral strain switch from R5 to X4 may further deteriorate thymic function, contributing to $\mathrm{CD}^{+}{ }^{+} \mathrm{T}$ cell depletion and HIV-1 disease progression.

\section{Both viral and host factors play determinant roles}

HIV-1 infection within the thymus may lead to viral clearance or steady-state viral levels. To identify elements that control different infection trajectories, we implement uncertainty and sensitivity analyses for all parameters in this model (cf. ref. 42). Detailed methods for these analyses are discussed in the Appendix. Our model reveals that changes in only certain parameters lead to different infection outcomes. We briefly summarize them below.

First, the rate of viral influx from blood $\left(s^{R}, s^{X}\right)$ greatly controls infection outcome. Infection within the thymus occurs only when the rate of viral influx is above a certain value. This finding is supported by two recent clinical studies, ${ }^{6,12}$ suggesting that thymic infection with HIV-1 can be controlled by halting viral influx from blood. The half-saturation constant of the viral input $\left(c_{4}\right)$ governs the speed at which virus establishes in-

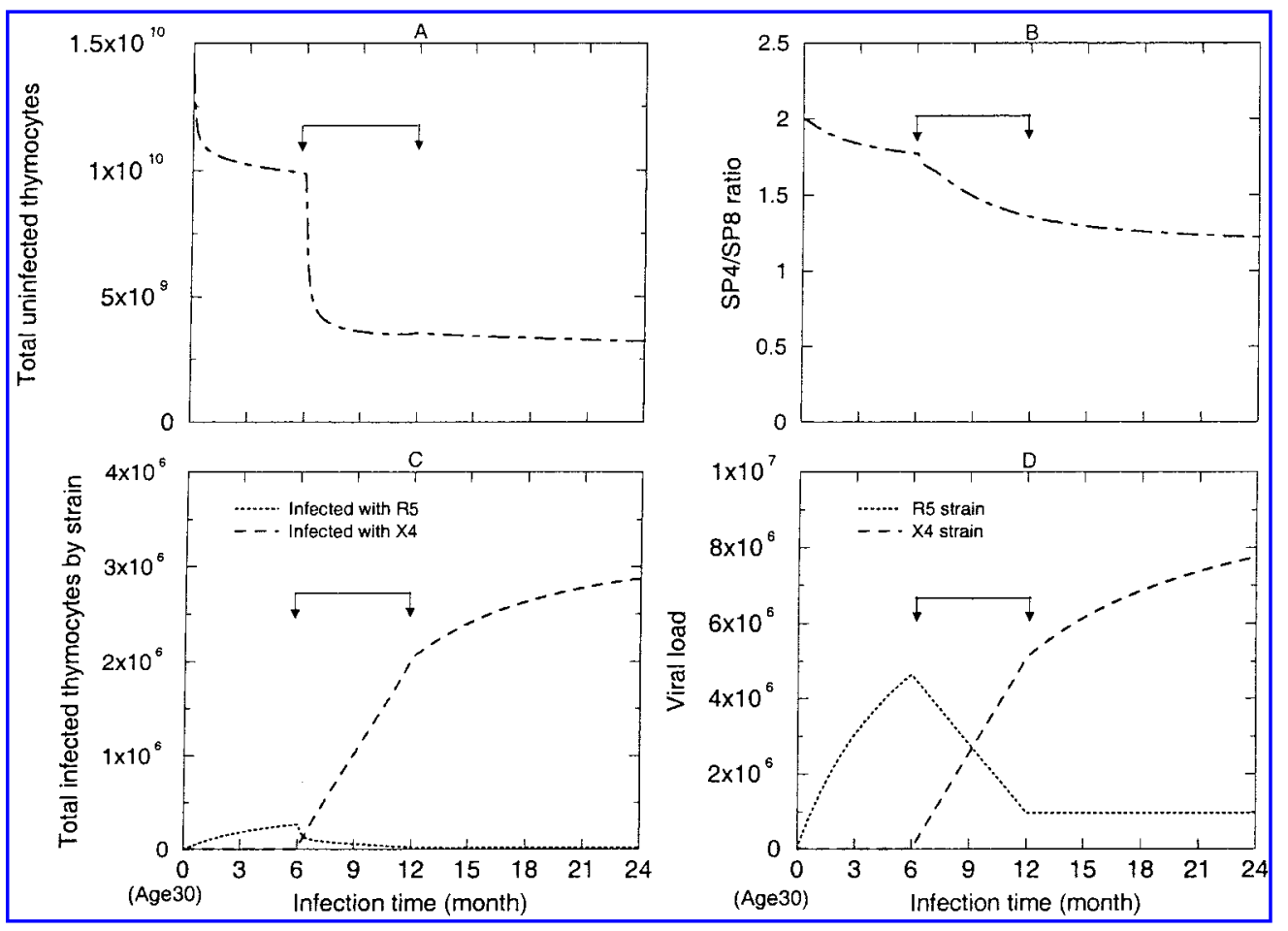

FIG. 5. Simulations of viral strain switch from R5 to X4 occurring over a 6-month period after 6 months of thymic infection in virtual adult patients. Arrows point to the time period when the viral strain switch occurs followed by the 6 month duration to complete the switch. (A) The total uninfected thymocytes, (B) the SP4/SP8 ratio, (C) the total infected thymocytes by strain, and (D) the intrathymic viral load. 
fection within the thymus; the lower its value, the quicker infection is established in the thymus (data not shown).

Second, virulence of HIV-1 strains, represented by both infection rates $(\beta)$ and viral production rates $(p)$, also govern infection outcomes. If infection rates or viral production rates reach critical values, the thymus remains infected even after viral influx from the blood is halted. This finding indicates that control of viral replication within the thymus is especially important for more virulent strains. In our model, we assume that X4 strains infect more thymocyte subsets, and these infected thymocytes generate more virions per cell as compared with R5 infection. If viral influx from blood is depleted, R5 infection within the thymus is not sustained, and the system moves to the uninfected state. However, X4 infection within the thymus is maintained when the rate of viral influx is zero, since a greater number of virions are generated.

Finally, three half-saturation constants that control the stem cell source from bone marrow $\left(c_{1}\right)$, maximal number of thymocytes in the TES region $\left(c_{2}\right)$, and enhanced death of uninfected thymocytes $\left(c_{3}\right)$ represent the thymic response to HIV1 infection. Varying $c_{1}$ directly affects the TN population, while varying $c_{2}$ and $c_{3}$ affects all thymocyte populations. When these three parameters are increased, the thymus resists adverse effects caused by HIV-1, such as reduced stem cells from bone marrow (or reduced use of stem cells), accelerated thymus atrophy, and enhanced death of thymocytes. Taken together, these results suggest that improving inherent thymic function is a viable target to controlling infection beyond directly controlling viral replication in both blood and thymus.

\section{DISCUSSION}

This study explores thymic infection with different HIV-1 strains and evaluates its potential impact on peripheral $\mathrm{T}$ cell homeostasis. Our mathematical models demonstrate that different viral strains can induce thymic dysfunction to varying degrees, which is supported by variations observed both clinically and experimentally. ${ }^{13,20,22}$ Primary infection with X4 (R5X4) strains or an early viral strain switch from R5 to X4 (R5X4) aggressively destroys thymic function and exports a greater amount of infected $\mathrm{T}$ cells and virus to the periphery. Recent data suggest that the thymus might be a source of HIV1 latently infected cells by exporting these cells to the periphery. ${ }^{43}$ Our model also indicates that thymic dysfunction accelerates HIV-1 disease progression, especially in pediatric patients whose thymus is more active and whose immune system has not yet fully developed.

Simulations of the number of CD $4^{+}$RTE per day during X4 or R5 infection correlate with peripheral CD $4^{+} \mathrm{T}$ cell counts in HIV-1-infected children previously defined as having or not a "thymic dysfunction" profile. ${ }^{13}$ Our model suggests that X4 infection induces a decrease in the rate of exported CD4 ${ }^{+} \mathrm{RTE}$, which accounts for the low number of blood CD4 ${ }^{+} \mathrm{T}$ cells in children with "thymic dysfunction" profile. A study of HIV-1infected children with either R5 or X4 strains determined that differences in the decrease of $\mathrm{CD} 4^{+} \mathrm{T}$ cell counts and TREC levels were mainly due to a lower production of new $\mathrm{CD} 4^{+} \mathrm{T}$ cells by the thymus. ${ }^{44}$ It was hypothesized that this occurred as a consequence of the inhibitory effect of different viral strains on thymic function, which is consistent with our modeling results.

Our model also demonstrates a decreased export rate of $\mathrm{CD}^{+}{ }^{+} \mathrm{RTE}$ during either R5 or X4 infection (data not shown). Our results are supported by experimental data showing that a loss of naive $\mathrm{CD} 8^{+} \mathrm{T}$ cells occurs at the same rate as the loss of naive $\mathrm{CD} 4{ }^{+}$cells. ${ }^{45}$ For children with thymic dysfunction, our model suggests a decrease in the exported rate of $\mathrm{CD}^{+}$ RTE is responsible for low counts of $\mathrm{CD}^{+} \mathrm{T}$ cells. Both very low $\mathrm{CD}^{+}$and $\mathrm{CD}^{+}{ }^{+} \mathrm{T}$ cell counts in the periphery induce $\mathrm{T}$ cell immunodeficiency and early progression of disease in children with thymus dysfunction. For children without thymus dysfunction, peripheral CD8 ${ }^{+} \mathrm{T}$ cell numbers increase, ${ }^{13}$ even with the decline of $\mathrm{CD} 8^{+} \mathrm{RTE}$ as predicted by our model. This is due to peripheral $\mathrm{CD} 8^{+} \mathrm{T}$ cell proliferation, which usually occurs in the early phase of HIV-1 infection. ${ }^{32,46}$ The expansion of $\mathrm{CD}^{+} \mathrm{T}$ cells compensates for the decrease of thymic output. This suggests that $\mathrm{CD} 8^{+} \mathrm{RTE}$ exported to the periphery are still functional and can proliferate in response to antigen stimulation. Proliferation of peripheral $\mathrm{CD}^{+} \mathrm{T}$ cells may also be strongly correlated with $\mathrm{CD} 4^{+} \mathrm{T}$ helper cell function.

Our model suggests that differences between R5 and X4 strains can explain the different immunophenotypes in pediatric patients and that thymic dysfunction in HIV-1-infected children could be due to infection with X4 strains. Although viral phenotypes were not analyzed in the study of Kourtis et al., ${ }^{13}$ one study supports our hypothesis showing that children infected with $\mathrm{X} 4$ strains have significantly lower numbers of both peripheral $\mathrm{CD}^{+}{ }^{+} \mathrm{T}$ cells and thymic production of new $\mathrm{T}$ cells as compared with children infected with R5 strains. ${ }^{44}$ Vertical transmission of R5X4 or X4 strains has also been observed in HIV-1-infected pediatric patients. ${ }^{47,48}$ Certainly, additional work will be necessary to characterize viral strains isolated from thymus and other compartments in patients with thymic dysfunction. Further, thymic output constitutes the majority of newly generated $\mathrm{T}$ cells in children, and only a small percentage of newly generated $\mathrm{T}$ cells is derived from peripheral proliferation; this is in contrast to adults. ${ }^{35}$ Thus, treatment strategies aimed at improving thymic function are especially important for HIV-1-infected children.

Adult thymic infection has also been explored in this paper. Several studies have shown that the adult thymus is still functional in many individuals and can contribute new cells to the peripheral T cell pool. ${ }^{49,50}$ Our model reveals that X4 strains are more virulent than $\mathrm{R} 5$ strains during adult thymic infection and can accelerate disease progression. Further, the decrease in RTE during either R5 or X4 infection can explain the decrease observed in TREC concentrations during primary infection.

Our model provides a virtual system with which to identify key players controlling thymic infection outcomes. These key players include viral influx from blood into the thymus, viral replication abilities within the thymus, the number of progenitor cells from bone marrow, and inherent thymic function. Our findings suggest strategies aimed at improving thymic function during HIV-1 treatment. Our model would likely predict that suppression of peripheral viral load through HAART would greatly benefit thymic function recovery. Thymic infection can also be controlled if certain treatment drugs are able to cross the blood-thymus barrier to directly inhibit viral replication within the thymus. In addition, our model predicts that treatment aimed at 
improving bone marrow function, improving inherent thymic function such as recovery of stromal cell function, limiting thymic inflammation, and normalizing the cytokine network each would aid recovery as well (cf. ref. 50a).

Our work focuses on exploring factors related to HIV-1 differential coreceptor utilization. R5 and X4 strains considered in our model may also represent any two strains differing in thymic tropism and virulence. One study has shown that thymus-derived HIV-1 strains have a higher affinity for thymocytes than clones isolated from other compartments, and further that their genotypes and phenotypes are different. ${ }^{51}$ Apart from viral phenotypes, factors such as host susceptibility to specific strains or host immune status may also explain varying degrees of thymic dysfunction. X4 strains were undetectable in the blood of many individuals with lower TREC levels, and some HIV-1-infected individuals have normal levels of TREC. ${ }^{11}$ This evidence implies that thymic function may be affected differently from person to person by the same HIV-1 strains, or that only specific strains can cross the blood-thymus barrier. Another possibility is that TREC levels measured in peripheral blood mononuclear cells (PBMC) ${ }^{11}$ may not represent thymic output correctly due to the influence of peripheral $\mathrm{T}$ cell dynamics. ${ }^{7}$ The time of vertical transmission may also be relevant for pediatric infection. Prenatal infection with R5 strains would have a more severe impact on $\mathrm{CD}^{+}{ }^{+} \mathrm{T}$ lymphocyte depletion than intrapartum infection with R5 strain, since thymopoiesis is interrupted shortly after its initiation. ${ }^{14}$

\section{APPENDIX}

\section{Model equations}

Five uninfected thymocyte subsets are defined as $T$ representing TN cells, $I$ representing ITTP cells, $D$ representing DP cells, $S_{4}$ representing SP4 cells, and $S_{8}$ representing SP8 cells. The equations for these uninfected thymocyte subsets during HIV-1 infection are as follows:

$$
\begin{gathered}
\frac{d T}{d t}=s(t)-\frac{\frac{s(t)}{2}\left(R_{5}+X_{4}\right)}{c_{1}+\left(R_{5}+X_{4}\right)} \\
+r_{1}\left[1-\frac{z(t)}{\left.k(t)-\frac{\frac{k(t) R_{5}}{4\left(c_{2}\right.}+\frac{\left.R_{5}\right)}{2\left(c_{2}\right.}+\frac{\left.X_{4}\right)}{k(t) X_{4}}}{X_{4}}\right] T-f_{1} T}\right. \\
\quad-\left(d_{1}+\frac{\left.m_{1} \frac{R_{5}}{c_{3}}+\frac{n_{1}}{R_{5}}+\frac{X_{4}}{c_{3}+X_{4}}\right) T}{\text { (1) }}\right.
\end{gathered}
$$

$$
\begin{aligned}
\frac{d I}{d t}=f_{1} T+r_{2} & {\left[1-\frac{z(t)}{k(t)-\frac{k(t)}{4\left(c_{2}\right.} \frac{R_{5}}{\left.R_{5}\right)} \frac{k(t)}{2\left(c_{2}+X_{4}\right)}}\right] I-f_{2} I } \\
& -\left(d_{2}+\frac{m_{2} R_{5}}{c_{3}+R_{5}}+\frac{n_{2}}{c_{3}+X_{4}}\right) I-\beta_{1}^{X} X_{4} I
\end{aligned}
$$

$$
\begin{aligned}
& \frac{d D}{d t}=f_{2} I \\
& +r_{3}\left[1-\frac{z(t)}{\left.k(t)-\frac{(t) R_{5}}{4\left(c_{2}\right.}+R_{5}\right)}-\frac{k(t)}{2\left(c_{2}+X_{4}\right.}\right] D-f_{3} D-f_{4} D
\end{aligned}
$$

$$
-\left(d_{3}+\frac{m_{3} R_{5}}{c_{3}+R_{5}}+\frac{n_{3} X_{4}}{c_{3}+X_{4}}\right) D-\beta_{1}^{R} R_{5} D-\beta_{2}^{X} X_{4} D
$$

$$
\begin{aligned}
\frac{d S_{4}}{d t} & =f_{3} D \\
& +r_{4}\left[1-\frac{z(t)}{k(t)-\frac{\left.k(t) \frac{R_{5}}{4\left(c_{2}\right.}+R_{5}\right)}{2\left(c_{2}+X_{4}\right)}}\right] \frac{\frac{X_{4}}{k(t)}}{S_{4}-e_{1} S_{4}} \\
& -\left(d_{4}+\frac{m_{4}}{\left.c_{3}+\frac{R_{5}}{R_{5}}+\frac{n_{4}}{c_{3}+X_{4}}\right) S_{4}-\beta_{2}^{R} R_{5} S_{4}-\beta_{3}^{X} X_{4} S_{4}}\right.
\end{aligned}
$$

$$
\begin{aligned}
& \frac{d S_{8}}{d t}=f_{4} D \\
& +r_{5}\left[1-\overline{k(t)-\frac{z(t)}{4\left(c_{2}+R_{5}\right)}-\frac{R_{5}}{2\left(c_{2}+X_{4}\right)}}\right] S_{8}-e_{2} S_{8} \\
& -\left(\frac{d_{5}+m_{5} R_{5}}{c_{3}+R_{5}}+\frac{n_{5} X_{4}}{c_{3}+X_{4}}\right) S_{8}
\end{aligned}
$$

The notations for variables and parameters in Eqs. (1)-(5) relating with normal human thymopoiesis are discussed in our previous paper. ${ }^{7}$ Thymocytes have a loss term representing direct HIV-1 infection. Target cells are determined based on the surface expression of HIV-1 receptor and coreceptor. ${ }^{16-18}$ ITTP cells are directly infected by X4 strains and DP and SP4 cells are directly infected by both R5 and X4 strains. Thymocyte loss is also due to indirect mechanisms such as infection of stromal cells, ${ }^{52,53}$ alteration of the cytokine network, ${ }^{54,55}$ and infection of hemopoietic progenitor cells. ${ }^{56,57}$ Our model captures these mechanisms as follows. First, the maximal number of thymocytes in the TES region, $k(t)$, is reduced in response to intrathymic viral load, since marked involution of the TES region has been reported in HIV-1-infected individuals. ${ }^{8-10}$ Second, uninfected thymocytes in multiple stages are induced into apoptosis, largely including uninfected cells. ${ }^{30,58}$ Thus in Eqs. (1)-(5), each subset of thymocytes has an enhanced death term to account for enhanced apoptosis. Third, the second term in Eq. (1) represents the decrease in cell source from the bone marrow, which correlates with viral load in the thymus. Here we use intrathymic viral load to represent bone marrow viral load, assuming viral load in these two compartments is correlated. Another interpretation for this term is the reduced use of cell source by the thymus, as thymic function determines the recovery of normal $\mathrm{T}$ cell subsets after bone marrow transplantation. ${ }^{59,60}$

Equations (6)-(8) represent the rate of change of R5-infected thymocyte subsets, where the superscript $R$ indicates infected cell class.

$$
\begin{aligned}
\frac{d D^{R}}{d t} & =\beta_{1}^{R} R_{5} D-f_{1}^{R} D^{R}-f_{2}^{R} D^{R}-d_{1}^{R} D^{R} \\
\frac{d S_{4}^{R}}{d t} & =f_{1}^{R} D^{\mathrm{R}}+\beta_{2}^{R} R_{5} S_{4}-e_{1}^{R} S_{4}^{R}-d_{2}^{R} S_{4}^{R} \\
\frac{d S_{8}^{R}}{d t} & =f_{2}^{R} D^{\mathrm{R}}-e_{2}^{R} S_{8}^{R}-d_{3}^{R} S_{8}^{R}
\end{aligned}
$$

Thymocytes are activated during thymopoiesis, undergoing proliferation, differentiation, and death. ${ }^{61}$ Thus, once thymocytes are infected by HIV-1, we assume they are productively infected. During R5 infection, DP and SP4 cells are directly in- 
fected to give rise to R5-infected DP and SP4 cells. R5-infected DP cells continue to differentiate into R5-infected SP4 and SP8 cells. The presence of infected SP8 cells (which lack a CD4 receptor) is suggested by experimental data indicating that infected thymocytes differentiate into mature, productively infected SP8 cells containing proviral DNA and are able to express viral RNA. ${ }^{62,63}$ Equations for rates of change for both R5infected SP4 and SP8 cells have loss terms representing emigration to the blood. Each equation for an infected subset of thymocytes also has a death term. It has been suggested that loss of thymocytes is due to direct killing of infected thymocytes, including syncytium formation, destruction of plasma membrane during viral budding. ${ }^{64}$

The equation for the rate of change of R5 virus is:

$$
\begin{aligned}
\frac{d R_{5}}{d t}=s^{R}(t)+p_{1}^{R} d_{1}^{R} D^{R}+p_{2}^{R} & d_{2}^{R} S_{4}^{R} \\
& +p_{3}^{R} d_{3}^{R} S_{8}^{R}-\epsilon^{R} R_{5}-\delta^{R} R_{5}
\end{aligned}
$$

where

$$
s^{R}(t)=\frac{s_{0}^{R} t}{c_{4}} \frac{t}{+t}
$$

is the rate of viral influx from blood.

No literature indicates how and when HIV-1 migrates into the thymus. It has been suggested that the decrease in TREC can occur relatively early during HIV-1 infection in infants. ${ }^{12} \mathrm{~A}$ progressive decline in TREC concentrations was seen in adults soon after HIV-1 seroconversion. ${ }^{11}$ During primary HIV-1 infection, both a wide dissemination of virus and seeding of lymphoid organs occur. ${ }^{65}$ Thus, we assume that virus gets into the thymus during early primary infection.

It has been shown that the number of thymocytes positive for viral RNA in SIV-infected rhesus monkeys correlates with the level of serum antigen, ${ }^{39}$ suggesting intrathymic viral load correlates with plasma viral load. In our virtual infection model, we assume the rate of viral influx from blood, $s^{R}(t)$, reaches a constant level after a period of time [Eq. (10)], since after peaking during primary infection, plasma viral load is stably maintained for several years prior to progression to AIDS stage. ${ }^{65}$

In Eq. (9), the rate of change of R5 virus is increased by viral production from R5-infected DP, SP4, and SP8 cells, respectively. Here we assume viral mutation does not occur in the thymus so that R5-infected cells generate only R5 virus. Loss of R5 virus is due to clearance within the thymus and emigration to the blood.

Equations (11)-(16) represent the rates of change of X4-infected thymocyte subsets together with the rate of change of the X4 strains. These equations are similar to those for the R5infected thymocyte subsets and R5 virus, with the exception that X4 strains have one more target cell population, ITTP cells, as they express high level of CXCR4. We also assume that R5 and X4 strains have similar access to the thymus [see Eqs. (10) and (16)].

$$
\begin{aligned}
& \frac{d I^{X}}{d t}=\beta_{1}^{X} X_{4} I-f_{1}^{X} I^{X}-d_{1}^{X} I^{X} \\
& \frac{d D^{X}}{d t}=f_{1}^{X} I^{X}+\beta_{2}^{X} X_{4} D-f_{2}^{X} D^{X}-f_{3}^{X} D^{X}-d_{2}^{X} D^{X}
\end{aligned}
$$

$$
\begin{aligned}
\frac{d S_{4}^{X}}{d t} & =f_{2}^{X} D^{X}+\beta_{3}^{X} X_{4} S_{4}-e_{1}^{X} S_{4}^{X}-d_{3}^{X} S_{4}^{X} \\
\frac{d S_{8}^{X}}{d t} & =f_{3}^{X} D^{X}-e_{2}^{X} S_{8}^{X}-d_{4}^{X} S_{8}^{X} \\
\frac{d X_{4}}{d t} & =s^{X}(t)+p_{1}^{X} d_{1}^{X} I^{X}+p_{2}^{X} d_{2}^{X} D^{X}+p_{3}^{X} d_{3}^{X} S_{4}^{X} \\
& +p_{4}^{X} d_{4}^{X} S_{8}^{X}-\epsilon^{X} X_{4}-\delta^{X} X_{4}
\end{aligned}
$$

where

$$
s^{X}(t)=\frac{s_{0}^{X} t}{c_{4}+t}
$$

is the rate of viral influx from blood.

\section{Parameter estimation}

The variables and parameters related to normal human thymopoiesis have been defined in our previous paper. ${ }^{7}$ The initial values for infected cell populations and viral strains are all 0 to ensure the thymus initially remains uninfected before the influx of virus from blood.Different parameter values are used for R5 or X4 infection according to literature reports (Table 2).

Infection rates, $\beta_{j}^{i}(i \in R, X, j \in 1,2,3)$, are estimated based on relative surface expression of coreceptor CCR5 and CXCR4 on thymocytes. ${ }^{16-17}$ As suggested in the literature, the amount of proviral DNA detected after infection with R5 or X4 strains is correlated with relative CCR5 or CXCR4 surface expression. ${ }^{16,21}$ Extra death rates of uninfected thymocytes, $m_{i}$ and $n_{i}$ ( $i \in 1,2,3,4,5$ ), are estimated based on the apoptosis rate of thymocytes. ${ }^{8,30}$

No data exist regarding differentiation rates of infected thymocytes. We speculate that HIV-1 infection impairs the maturation process based on a decrease in total thymocyte number. ${ }^{8-10}$ Thus half-normal values of differentiation rates are used for the corresponding infected thymocyte subsets, $f_{j}^{i}(i \in R, X, j \in 1,2,3)$. Similarly, we use half-normal values of emigration rates for infected SP4 and SP8 cells, $e_{j}^{i}(i \in R, X, j \in 1,2)$. X4 strains rapidly and efficiently kill thymocytes as compared with the R5 strains, and infected thymocytes have higher death rates than uninfected cells. ${ }^{20,66}$ Taking these factors into account, a 2-fold higher rate is used for the death rate of R5-infected cells and 3-fold higher rate is used for X4-infected cells, $d_{j}^{i}(i \in R, X, j \in 1,2,3,4)$.

Productively infected cells in the lymphoid tissue and blood have viral RNA copy numbers in the range of 20-200 per cell. ${ }^{67}$ Mature SP4 and SP8 thymocytes are able to sustain a high level of HIV-1 replication, while immature thymocytes produce significantly less. This phenomenon correlates with stage-specific activation and maturation..$^{21,54} \mathrm{X} 4$-infected cells produce more virions than R5-infected cells. ${ }^{20,21}$ We estimate the viral production rate for each infected thymocyte subset, $p_{j}^{i}(i \in R, X, j$ $\in 1,2,3,4)$, according to the above evidence.

No data are available regarding viral transport from blood into the thymus. The maximal value of the rate of viral influx we used in this model, $s_{0}^{i}(i \in \mathrm{R}, \mathrm{X})$ is estimated from our simulations (using uncertainty and sensitivity analyses). A 2-fold higher rate of viral influx is used for children, as HIV-1 levels in children remain high during the first 2 years of life. ${ }^{33}$ Data on the clearance rate of HIV-1 in blood are calculated to be 
Table 2. Parameter Estimation in the Model of Thymic Infection with HiV-1

\begin{tabular}{|c|c|c|c|c|}
\hline Parameter & Definition & Value & Unit & References \\
\hline$\beta_{1}^{R}$ & Infection rate of DP cells with R5 & $5 \times 10^{-12}$ & /day $\cdot$ virus & 16-18, estimated \\
\hline$\beta_{2}^{R}$ & Infection rate of SP4 cells with R5 & $10^{-12}$ & /day $\cdot$ virus & 16-18, estimated \\
\hline$\beta_{1}^{\bar{X}}$ & Infection rate of ITTP cells with $\mathrm{X} 4$ & $5 \times 10^{-10}$ & /day $\cdot$ virus & 16-18, estimated \\
\hline$\beta_{2}^{\dot{X}}$ & Infection rate of DP cells with $\mathrm{X} 4$ & $10^{-10}$ & /day $\cdot$ virus & 16-18, estimated \\
\hline$\beta_{3}^{X}$ & Infection rate of SP4 cells with $\mathrm{X} 4$ & $2 \times 10^{-11}$ & /day $\cdot$ virus & 16-18, estimated \\
\hline$m_{1}$ & Enhanced death rate of uninfected TN cells during R5 infection & 0.06 & /day & 8,30 , estimated \\
\hline$m_{2}$ & Enhanced death rate of uninfected ITTP cells during R5 infection & 0.04 & /day & 8,30 , estimated \\
\hline$m_{3}$ & Enhanced death rate of uninfected DP cells during R5 infection & 0.2 & /day & 8,30 , estimated \\
\hline$m_{4}$ & Enhanced death rate of uninfected SP4 cells during R5 infection & 0.11 & /day & 8,30 , estimated \\
\hline$m_{5}$ & Enhanced death rate of uninfected SP8 cells during R5 infection & 0.03 & /day & 8,30 , estimated \\
\hline$n_{1}$ & Enhanced death rate of uninfected TN cells during X4 infection & 0.21 & /day & 8,30 , estimated \\
\hline$n_{2}$ & Enhanced death rate of uninfected ITTP cells during X4 infection & 0.14 & /day & 8,30 , estimated \\
\hline$n_{3}$ & Enhanced death rate of uninfected DP cells during X4 infection & 0.33 & /day & 8,30 , estimated \\
\hline$n_{4}$ & Enhanced death rate of uninfected SP4 cells during X4 infection & 0.26 & /day & 8,30 , estimated \\
\hline$n_{5}$ & Enhanced death rate of uninfected SP8 cells during X4 infection & 0.03 & /day & 8,30 , estimated \\
\hline$f_{1}^{X}$ & Differentiation rate of X4-infected ITTP cells into DP cells & 0.25 & /day & Estimated \\
\hline$f_{1}^{k}\left(f_{2}^{X}\right)$ & Differentiation rate of R5(X4)-infected DP cells into SP4 cells & 0.02 & /day & Estimated \\
\hline$f_{2}^{R}\left(f_{3}^{\bar{X}}\right)$ & Differentiation rate of R5(X4)-infected DP cells into SP8 cells & 0.01 & /day & Estimated \\
\hline$e_{1}^{R}\left(e_{1}^{X}\right)$ & Emigration rate of R5(X4)-infected SP4 cells & 0.04 & /day & Estimated \\
\hline$e_{2}^{R}\left(e_{2}^{X}\right)$ & Emigration rate of R5(X4)-infected SP8 cells & 0.04 & /day & Estimated \\
\hline$d_{1}^{R}$ & Death rate of R5-infected DP cells & 0.66 & /day & 20,66, estimated \\
\hline$d_{2}^{R}$ & Death rate of R5-infected SP4 cells & 0.53 & /day & 20,66 , estimated \\
\hline$d_{3}^{R}$ & Death rate of R5-infected SP8 cells & 0.53 & /day & 20,66, estimated \\
\hline$d_{1}^{X}$ & Death rate of X4-infected ITTP cells & 0.51 & /day & 20,66, estimated \\
\hline$d_{2}^{X}$ & Death rate of X4-infected DP cells & 1.00 & /day & 20,66, estimated \\
\hline$d_{3}^{\bar{X}}$ & Death rate of X4-infected SP4 cells & 0.79 & /day & 20,66, estimated \\
\hline$d_{4}^{X}$ & Death rate of X4-infected SP8 cells & 0.79 & /day & 20,66, estimated \\
\hline$p_{1}^{R}$ & $\mathrm{R} 5$ production rate by $\mathrm{R} 5$-infected DP cells & 10 & Virus/cell & $20,54,67$ \\
\hline$p_{2}^{R}$ & R5 production rate by $\mathrm{R} 5$-infected SP4 cells & 100 & Virus/cell & $20,54,67$ \\
\hline$p_{3}^{R}$ & R5 production rate by $\mathrm{R} 5$-infected SP8 cells & 100 & Virus/cell & $20,54,67$ \\
\hline$p_{1}^{X}$ & $\mathrm{X} 4$ production rate by $\mathrm{X} 4$-infected ITTP cells & 20 & Virus/cell & $20,54,67$ \\
\hline$p_{2}^{X}$ & $\mathrm{X} 4$ production rate by $\mathrm{X} 4$-infected DP cells & 20 & Virus/cell & $20,54,67$ \\
\hline$p_{3}^{X}$ & $\mathrm{X} 4$ production rate by $\mathrm{X} 4$-infected SP4 cells & 200 & Virus/cell & $20,54,67$ \\
\hline$p_{4}^{X}$ & $\mathrm{X} 4$ production rate by $\mathrm{X} 4$-infected SP8 cells & 200 & Virus/cell & $20,54,67$ \\
\hline$s_{0}^{R}\left(s_{0}^{X}\right)$ & Maximum input of R5 from blood to the thymus & $\begin{array}{l}2 \times 10^{9} \\
\text { children }\end{array}$ & Virus/day & 33, estimated \\
\hline & & $10^{9}$ adults & Virus/day & 33, estimated \\
\hline$\delta^{R}\left(\delta^{X}\right)$ & Clearance rate of $\mathrm{R} 5(\mathrm{X} 4)$ within the thymus & 3.1 & /day & 68 \\
\hline$\epsilon^{R}\left(\epsilon^{X}\right)$ & Export rate of R5(X4) from the thymus to blood & 100 & /day & Estimated \\
\hline$c_{1}$ & Half-saturation constant, virus on cell source & $10^{6}$ & Virus & Estimated \\
\hline$c_{2}$ & Half-saturation constant, virus on TES region & $10^{5}$ & Virus & Estimated \\
\hline$c_{3}$ & Half-saturation constant, virus on enhanced death rate & $10^{7}$ & Virus & Estimated \\
\hline$c_{4}$ & Half-saturation constant, time on rate of viral influx from blood & 200 & Day & Estimated \\
\hline
\end{tabular}

$3.1 /$ day. ${ }^{68}$ We use this same estimate for the clearance rate of virus from the thymus, $\delta^{i}(i \in R, X)$. Viral export from the thymus, $\epsilon^{i}(i \in R, X)$, is estimated from model simulations, as no data exist on this value.

Finally, three half-saturation constants, $c_{i}(i \in 1,2,3)$, representing the effects of HIV-1 on the cell source, TES region, and enhanced death rates, are estimated through model simulations.
The time for the rate of viral influx to reach half-saturation level, $c_{4}$, is determined at Day 200, since clinical data indicate that plasma viral load reaches relatively stable levels after 200 days of primary infection..$^{65,69}$

Once the model equations are established together with the values for the parameters, we solve the system of ordinary differential equations using two appropriate numerical methods. 


\section{Uncertainty and sensitivity analysis}

We use Latin hypercube sampling and partial rank correlation (PRC) (cf. ref. 42) for uncertainty and sensitivity analyses, respectively. For the uncertainty analysis, a random sample of each of the parameters to be tested is generated from a file of parameter ranges and distributions. The sets of parameter values are randomly chosen and then used in independent simulations. This provides a range of results for each solution curve generated from the original parameter set. The sensitivity analysis is used to determine which parameter(s) have the greatest influence on the variation in outcomes resulting from the uncertainty analysis. By comparing coefficients of PRC, the relative importance of individual parameters can be quantitatively evaluated.

\section{ACKNOWLEDGMENTS}

This work was supported by National Institutes of Health Grant HL62119 and The Whitaker Foundation to D.E.K. and Elizabeth Glaser Pediatric AIDS Foundation Student Intern Award to P.Y.

\section{REFERENCES}

1. Kirschner D, Webb GF, and Cloyd M: Model of HIV-1 disease progression based on virus-induced lymph node homing and homing-induced apoptosis of $\mathrm{CD} 4^{+}$lymphocytes. J Acquir Immune Defic Syndr 2000;24:352-362.

2. Bajaria SH, Webb GF, Cloyd M, and Kirschner D: Dynamics of naive and memory $\mathrm{CD}^{+}{ }^{+} \mathrm{T}$ lymphocytes in HIV-1 disease progression. J Acquir Immune Defic Syndr 2002;30:41-58.

3. Wang L, Robb CW, and Cloyd MW: HIV induces homing of resting T lymphocytes to lymph nodes. Virology 1997;228:141-152.

4. Wang L, Chen JJ, Gelman BB, Konig R, and Cloyd MW: A novel mechanism of CD4 lymphocyte depletion involves effects of HIV on resting lymphocytes: Induction of lymph node homing and apoptosis upon secondary signaling through homing receptors. J Immunol 1999;162:268-276.

5. Lempicki RA, Kovacs JA, Baseler MW, et al.: Impact of HIV-1 infection and highly active antiretroviral therapy on the kinetics of $\mathrm{CD}^{+}$and $\mathrm{CD}^{+}{ }^{+} \mathrm{T}$ cell turnover in HIV-infected patients. Proc Natl Acad Sci USA 2000;97:13778-13783.

6. Douek DC, McFarland RD, Keiser PH, et al.: Changes in thymic function with age and during the treatment of HIV infection [see comments]. Nature 1998;396:690-695.

7. Ye $\mathrm{P}$ and Kirschner DE: Re-evaluation of $\mathrm{T}$ cell receptor excision circles as measurement of human recent thymic emigrants. $\mathrm{J} \mathrm{Im-}$ munol 2002;168:4968-4979.

8. Rosenzweig M, Clark DP, and Gaulton GN: Selective thymocyte depletion in neonatal HIV-1 thymic infection. AIDS 1993;7: 1601-1605.

9. Schuurman HJ, Krone WJ, Broekhuizen R, et al.: The thymus in acquired immune deficiency syndrome. Comparison with other types of immunodeficiency diseases, and presence of components of human immunodeficiency virus type 1. Am J Pathol 1989; 134:1329-1338.

10. Papiernik M, Brossard Y, Mulliez N, et al.: Thymic abnormalities in fetuses aborted from human immunodeficiency virus type 1 seropositive women. Pediatrics 1992;89:297-301.
11. Zhang L, Lewin SR, Markowitz M, et al.: Measuring recent thymic emigrants in blood of normal and HIV-1-infected individuals before and after effective therapy. J Exp Med 1999;190:725-732.

12. Douek DC, Koup RA, McFarland RD, Sullivan JL, and Luzuriaga $\mathrm{K}$ : Effect of HIV on thymic function before and after antiretroviral therapy in children. J Infect Dis 2000;181:1479-1482.

13. Kourtis AP, Ibegbu C, Nahmias AJ, et al.: Early progression of disease in HIV-infected infants with thymus dysfunction [published erratum appears in N Engl J Med 1997;336(8):595].N Engl J Med 1996;335:1431-1436.

14. Nahmias AJ, Clark WS, Kourtis AP, et al.: Thymic dysfunction and time of infection predict mortality in human immunodeficiency virus-infected infants. CDC Perinatal AIDS Collaborative Transmission Study Group. J Infect Dis 1998;178:680-685.

15. Meyers A, Shah A, Cleveland RH, et al.: Thymic size on chest radiograph and rapid disease progression in human immunodeficiency virus 1-infected children. Pediatr Infect Dis J 2001;20: $1112-1118$.

16. Zaitseva MB, Lee S, Rabin RL, et al.: CXCR4 and CCR5 on human thymocytes: Biological function and role in HIV-1 infection. J Immunol 1998;161:3103-3113.

17. Berkowitz RD, Beckerman KP, Schall TJ, and McCune JM: CXCR4 and CCR5 expression delineates targets for HIV-1 disruption of T cell differentiation. J Immunol 1998;161:3702-3710.

18. Kitchen SG and Zack JA: CXCR4 expression during lymphopoiesis: Implications for human immunodeficiency virus type 1 infection of the thymus. J Virol 1997;71:6928-6934.

19. Taylor JR Jr, Kimbrell KC, Scoggins R, Delaney M, Wu L, and Camerini D: Expression and function of chemokine receptors on human thymocytes: Implications for infection by human immunodeficiency virus type 1 . J Virol 2001;75:8752-8760.

20. Uittenbogaart CH, Anisman DJ, Jamieson BD, et al.: Differential tropism of HIV-1 isolates for distinct thymocyte subsets in vitro. AIDS 1996;10:F9-16.

21. Pedroza-Martins L, Gurney KB, Torbett BE, and Uittenbogaart CH: Differential tropism and replication kinetics of human immunodeficiency virus type 1 isolates in thymocytes: Coreceptor expression allows viral entry, but productive infection of distinct subsets is determined at the postentry level. J Virol 1998;72:9441-9452.

22. Berkowitz RD, Alexander S, Bare C, et al.: CCR5- and CXCR4utilizing strains of human immunodeficiency virus type 1 exhibit differential tropism and pathogenesis in vivo. $\mathrm{J}$ Virol 1998;72:10108-10117.

23. Kirschner DE, Mehr R, and Perelson AS: Role of the thymus in pediatric HIV-1 infection. J Acquir Immune Defic Syndr Hum Retrovirol 1998;18:95-109.

24. Berger EA, Doms RW, and Fenyo EM: A new classification for HIV-1 [letter]. Nature 1998;391:240.

25. Cornelissen M, Mulder-Kampinga G, Veenstra J, et al.: Syncytiuminducing (SI) phenotype suppression at seroconversion after intramuscular inoculation of a non-syncytium-inducing/SI phenotypically mixed human immunodeficiency virus population. J Virol 1995;69:1810-1818.

26. Tersmette M, de Goede RE, Al BJ, et al.: Differential syncytiuminducing capacity of human immunodeficiency virus isolates: Frequent detection of syncytium-inducing isolates in patients with acquired immunodeficiency syndrome (AIDS) and AIDS-related complex. J Virol 1988;62:2026-2032.

27. Connor RI, Sheridan KE, Ceradini D, Choe S, and Landau NR: Change in coreceptor use correlates with disease progression in HIV-1-infected individuals. J Exp Med 1997;185:621-628.

28. Richman DD and Bozzette SA: The impact of the syncytium-inducing phenotype of human immunodeficiency virus on disease progression. J Infect Dis 1994;169:968-974.

29. Kourtis AP, Bulterys M, Nesheim SR, and Lee FK: Understand- 
ing the timing of HIV transmission from mother to infant. JAMA 2001;285:709-712.

30. Su L, Kaneshima H, Bonyhadi M, et al.: HIV-1-induced thymocyte depletion is associated with indirect cytopathogenicity and infection of progenitor cells in vivo. Immunity 1995;2:25-36.

31. Bonyhadi ML, Rabin L, Salimi S, et al.: HIV induces thymus depletion in vivo. Nature 1993;363:728-732.

32. Margolick JB, Donnenberg AD, Munoz A, et al.: Changes in $\mathrm{T}$ and non-T lymphocyte subsets following seroconversion to HIV1: Stable $\mathrm{CD}^{+}$and declining $\mathrm{CD}^{-}$populations suggest regulatory responses linked to loss of CD4 lymphocytes. The Multicenter AIDS Cohort Study [see comments]. J Acquir Immune Defic Syndr 1993;6:153-161.

33. Luzuriaga $\mathrm{K}, \mathrm{Wu} \mathrm{H}, \mathrm{McManus} \mathrm{M}$, et al.: Dynamics of human immunodeficiency virus type 1 replication in vertically infected infants. J Virol 1999;73:362-367.

34. Kourtis AP, Ibegbu CC, Lee FK, Vogler L, Philips K, and Nahmias AJ: Decreases in $\mathrm{CD}^{+} \mathrm{B}$ lymphocytes in children with the DiGeorge anomaly. Scand J Immunol 1997;46:281-283.

35. Haynes BF and Hale LP: The human thymus. A chimeric organ comprised of central and peripheral lymphoid components [corrected and republished article originally printed in Immunol Res 1998;18(2):61-78]. Immunol Res 1998;18:175-192.

36. Simmons G, Wilkinson D, Reeves JD, et al.: Primary, syncytiuminducing human immunodeficiency virus type 1 isolates are dualtropic and most can use either Lestr or CCR5 as coreceptors for virus entry. J Virol 1996;70:8355-8360.

37. D'Aquila RT, Sutton L, Savara A, Hughes MD, and Johnson VA: CCR5/delta(ccr5) heterozygosity: A selective pressure for the syncytium-inducing human immunodeficiency virus type 1 phenotype. NIAID AIDS Clinical Trials Group Protocol 241 Virology Team. J Infect Dis 1998;177:1549-1553.

38. Muller JG, Krenn V, Schindler C, et al.: Alterations of thymus cortical epithelium and interdigitating dendritic cells but no increase of thymocyte cell death in the early course of simian immunodeficiency virus infection. Am J Pathol 1993;143:699-713.

39. Baskin GB, Murphey-Corb M, Martin LN, Davison-Fairburn B, Hu FS, and Kuebler D: Thymus in simian immunodeficiency virusinfected rhesus monkeys. Lab Invest 1991;65:400-407.

40. Zhang J, Gupta A, Dave R, Yimen M, Zerhouni B, and Saha K: Isolation of primary HIV-1 that target $\mathrm{CD} 8^{+} \mathrm{T}$ lymphocytes using CD8 as a receptor. Nature Med 2001;7:65-72.

41. Equils O, Garratty E, Wei LS, et al.: Recovery of replication-competent virus from $\mathrm{CD} 4 \mathrm{~T}$ cell reservoirs and change in coreceptor use in human immunodeficiency virus type 1-infected children responding to highly active antiretroviral therapy. $\mathrm{J}$ Infect Dis 2000;182:751-757.

42. Blower SM and Dowlatabadi H: Sensitivity and uncertainty analysis of complex models of disease transmission: An HIV model, as an example. Int Stat Rev 1994;62:229-243.

43. Brooks DG, Kitchen SG, Kitchen CM, Scripture-Adams DD, and Zack JA: Generation of HIV latency during thymopoiesis. Nature Med 2001;7:459-464.

44. Correa R and Munoz-Fernandez MA: Viral phenotype affects the thymic production of new T cells in HIV-1-infected children. AIDS 2001;15:1959-1963.

45. Roederer M, De Rosa SC, Watanabe N, and Herzenberg LA: Dynamics of fine T-cell subsets during HIV disease and after thymic ablation by mediastinal irradiation. Semin Immunol 1997;9:389-396.

46. Smith PR, Cavenagh JD, Milne T, et al.: Benign monoclonal expansion of $\mathrm{CD}^{+}$lymphocytes in HIV infection. $\mathrm{J}$ Clin Pathol 2000;53:177-181.

47. Ometto L, Zanchetta M, Mainardi M, et al.: Co-receptor usage of HIV-1 primary isolates, viral burden, and CCR5 genotype in mother-to-child HIV-1 transmission. AIDS 2000;14:1721-1729.
48. Zhang YJ, Dragic T, Cao Y, Kostrikis L, et al.: Use of coreceptors other than CCR5 by non-syncytium-inducing adult and pediatric isolates of human immunodeficiency virus type 1 is rare in vitro. J Virol 1998;72:9337-9344.

49. Jamieson BD, Douek DC, Killian S, et al.: Generation of functional thymocytes in the human adult. Immunity 1999;10:569-575.

50. Poulin JF, Viswanathan MN, Harris JM, et al.: Direct evidence for thymic function in adult humans. J Exp Med 1999;190: 479-486.

50a. Ye, P, Kourtis AP, Kerschner DE: Reconstitution of thymic function in HIV-1 patients treated with highly active anti-retroviral therapy. Clin Immunol 2002 (in press).

51. Calabro ML, Zanotto C, Calderazzo F, et al.: HIV-1 infection of the thymus: Evidence for a cytopathic and thymotropic viral variant in vivo. AIDS Res Hum Retroviruses 1995;11:11-19.

52. Cameron PU, Lowe MG, Sotzik F, Coughlan AF, Crowe SM, and Shortman K: The interaction of macrophage and non-macrophage tropic isolates of HIV-1 with thymic and tonsillar dendritic cells in vitro. J Exp Med 1996;183:1851-1856.

53. Braun J, Valentin H, Nugeyre MT, Ohayon H, Gounon P, and Barre-Sinoussi F: Productive and persistent infection of human thymic epithelial cells in vitro with HIV-1. Virology 1996;225: 413-418.

54. Chene L, Nugeyre MT, Guillemard E, Moulian N, Barre-Sinoussi $\mathrm{F}$, and Israel N: Thymocyte-thymic epithelial cell interaction leads to high-level replication of human immunodeficiency virus exclusively in mature $\mathrm{CD} 4(+) \mathrm{CD} 8(-) \mathrm{CD} 3(+)$ thymocytes: A critical role for tumor necrosis factor and interleukin-7. J Virol 1999;73: $7533-7542$.

55. Uittenbogaart $\mathrm{CH}$, Boscardin WJ, Anisman-Posner DJ, Koka PS, Bristol G, and Zack JA: Effect of cytokines on HIV-induced depletion of thymocytes in vivo. AIDS 2000;14:1317-1325.

56. Jenkins M, Hanley MB, Moreno MB, Wieder E, and McCune JM: Human immunodeficiency virus-1 infection interrupts thymopoiesis and multilineage hematopoiesis in vivo. Blood 1998;91: 2672-2678.

57. Koka PS, Jamieson BD, Brooks DG, and Zack JA: Human immunodeficiency virus type 1-induced hematopoietic inhibition is independent of productive infection of progenitor cells in vivo. $\mathrm{J} \mathrm{Vi-}$ rol 1999;73:9089-9097.

58. Iida T, Ichimura H, Shimada T, et al.: Role of apoptosis induction in both peripheral lymph nodes and thymus in progressive loss of $\mathrm{CD}^{+}{ }^{+}$cells in SHIV-infected macaques. AIDS Res Hum Retroviruses 2000;16:9-18.

59. Heitger A, Greinix H, Mannhalter C, et al.: Requirement of residual thymus to restore normal $\mathrm{T}$-cell subsets after human allogeneic bone marrow transplantation [see comments]. Transplantation 2000;69:2366-2373.

60. Roux E, Dumont-Girard F, Starobinski M, et al.: Recovery of immune reactivity after T-cell-depleted bone marrow transplantation depends on thymic activity. Blood 2000;96:2299-2303.

61. Kraft DL, Weissman IL, and Waller EK: Differentiation of $\mathrm{CD}^{-} 4^{-} 8^{-}$human fetal thymocytes in vivo: characterization of a $\mathrm{CD}^{-} 4^{+} 8^{-}$intermediate. J Exp Med 1993;178:265-277.

62. Kitchen SG, Uittenbogaart $\mathrm{CH}$, and Zack JA: Mechanism of human immunodeficiency virus type 1 localization in CD4-negative thymocytes: Differentiation from a CD4-positive precursor allows productive infection. J Virol 1997;71:5713-5722.

63. Lee S, Goldstein H, Baseler M, Adelsberger J, and Golding H: Human immunodeficiency virus type 1 infection of mature CD3hiCD8+ thymocytes. J Virol 1997;71:6671-6676.

64. Jamieson BD, Uittenbogaart CH, Schmid I, and Zack JA: High viral burden and rapid $\mathrm{CD}^{+}$cell depletion in human immunodeficiency virus type 1-infected SCID-hu mice suggest direct viral killing of thymocytes in vivo. J Virol 1997;71:8245-8253. 
65. Pennisi E and Cohen J: Eradicating HIV from a patient: Not just a dream? [news]. Science 1996;272:1884.

66. Camerini D, Su HP, Gamez-Torre G, Johnson ML, Zack JA, and Chen IS: Human immunodeficiency virus type 1 pathogenesis in SCID-hu mice correlates with syncytium-inducing phenotype and viral replication. J Virol 2000;74:3196-3204.

67. Haase AT: Population biology of HIV-1 infection: Viral and CD4 ${ }^{+}$ T cell demographics and dynamics in lymphatic tissues. Annu Rev Immunol 1999; 17:625-656.

68. Perelson AS, Neumann AU, Markowitz M, Leonard JM, and Ho DD: HIV-1 dynamics in vivo: Virion clearance rate, infected cell life-span, and viral generation time. Science 1996;271:1582-1586.
69. Kaufmann GR, Cunningham P, Kelleher AD, et al.: Patterns of viral dynamics during primary human immunodeficiency virus type 1 infection. The Sydney Primary HIV Infection Study Group. J Infect Dis 1998;178:1812-1815.

Address reprint requests to: Denise E. Kirschner Department of Microbiology and Immunology The University of Michigan Medical School Ann Arbor, MI 48109

E-mail:kirschne@umich.edu 
This article has been cited by:

1. Denise E. Kirschner, Stewart T. Chang, Thomas W. Riggs, Nicolas Perry, Jennifer J. Linderman. 2007. Toward a multiscale model of antigen presentation in immunity. Immunological Reviews 216:1, 93. [CrossRef]

2. Jeffrey M. Jacobson. 2005. Immune-based therapies: An adjunct to antiretroviral treatment. Current HIVIAIDS Reports 2:2, 90-97. [CrossRef] 